\title{
A Prognostics Framework for Power Semiconductor IGBT Modules through Monitoring of the On-State Voltage
}

\author{
Nicolas Degrenne ${ }^{1}$, Chihiro Kawahara ${ }^{2}$ and Stefan Mollov ${ }^{3}$ \\ ${ }^{1,2,3}$ Power Electronic System Division, Mitsubishi Electric R\&D Centre Europe, Rennes, France \\ n.degrenne@fr.merce.mee.com \\ c.kawahara@fr.merce.mee.com \\ s.mollov@fr.merce.mee.com
}

\begin{abstract}
This paper presents a literature review and an overview of original contributions on diagnostic and prognostic technologies for IGBT power modules based on the monitoring of the on-state voltage (Von). First, different kinds of Von sensing circuits are discussed in terms of specifications, implementation, performance and cost. A low-cost and practical circuit is experimentally demonstrated. Then, a method is presented and evaluated for estimating wire-bond degradation. Wire-bond lift-off is the most observable wear-out mechanism for industrial power semiconductor IGBT modules subject to active power cycling (Lutz et al., 2011). It is effectively detected by measuring Von at the Zero Temperature Coefficient (ZTC) current value. Next, a method is presented to estimate the die temperature. Knowing the die temperature allows estimating the thermo-mechanical stress imposed to the wire-bonds. It is demonstrated to be feasible with $\pm 3^{\circ} \mathrm{C}$ accuracy/precision using after careful calibration of Von as a Temperature Sensitive Electrical Parameter (TSEP). Finally, an algorithm is presented to process the information generated from the monitoring of Von and estimate the Remaining Useful Life (RUL). It considers Von evolution prior the first wire-bond lift-off and it combines both condition-based and damage accumulation based predictions. The major contribution of this paper is to present, for the first time, a complete framework for diagnostics and prognostics of power semiconductor IGBT modules.
\end{abstract}

\section{INTRODUCTION}

When designing for life-cycle cost, the power electronic designer faces the trade-off of reliability versus cost (Fig. 1). For increasing number of applications, lifetimes longer than

Nicolas Degrenne, Chihiro Kawahara and Stefan Mollov. This is an openaccess article distributed under the terms of the Creative Commons Attribution 3.0 United States License, which permits unrestricted use, distribution, and reproduction in any medium, provided the original author and source are credited. e.g. 30 years is unnecessary due to excessive acquisition cost and lifetime limitation of other components in the system.

Prognostics is defined as an engineering discipline focused on predicting the time at which a system or a component will no longer perform its intended function (Goebel et al., 2017). Prognostics technologies offer a paradigm shift to the power electronic designer: estimation and communication of the Remaining Useful Life (RUL) permit predictive maintenance and reduce the negative impact associated with reduced overdesign margin (e.g. security, availability, failure and unplanned maintenance cost) (Degrenne et al., 2015).

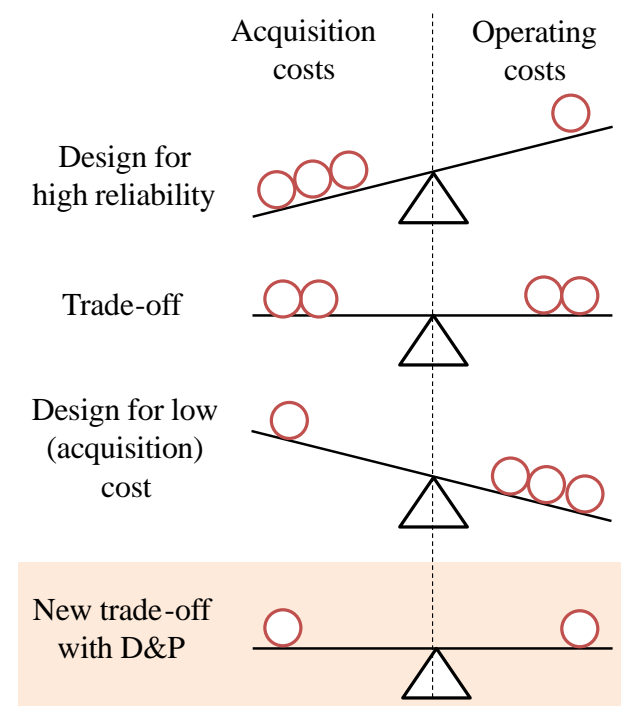

Figure 1. New design trade-off permitted by diagnostics and prognostics.

Condition-based predictions and Damage Accumulation Model (DAM) as defined in Goebel et al. (2017) respectively rely on the monitoring of failure precursors and stressors. When traditional wire-bonded power semi-conductor modules are concerned, these are typically the on-state voltage (Von) at high current and the die temperature $\mathrm{Tj}$. In 
the case of traditional power semi-conductor modules, Von mainly consists of the on-resistance of semiconductor dies and the resistance of bonding wires. Typical interconnection of power semi-conductor die in the power module and the equivalent circuit is shown in Fig. 2.

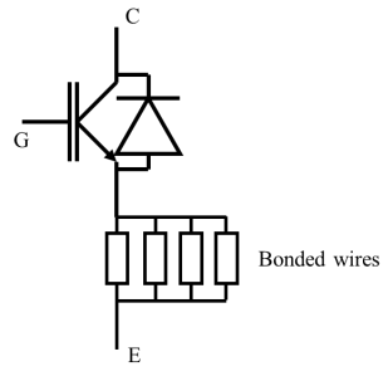

Figure 2. Schematic illustration of equivalent circuit of semi-conductor dies and bonded wires in power modules.

The on-state voltage of IGBT is a Temperature Sensitive Electrical Parameter (TSEP), and it thus can conceivably address both prognostics indicators through the same Von sensor in a low-cost and reliable manner.

This paper introduces the most recent state of the art and provides an overview of original contributions in the field on prognostics based on Von sensor. The paper presents in order (Fig. 3):

- Von sensors

- Estimation of electrical resistance increase

- Estimation of junction temperature

- Prediction of damage, EoL(End of Life) and RUL

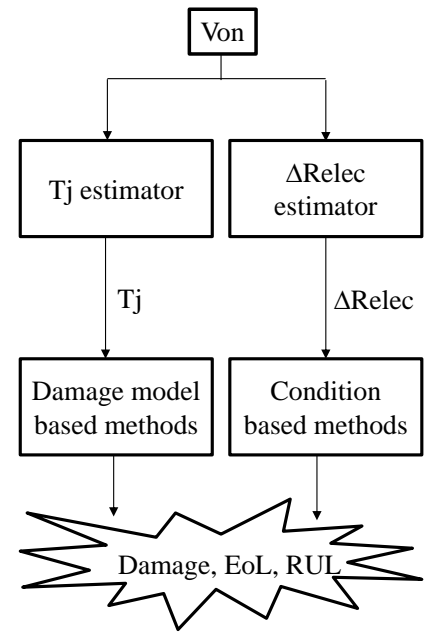

Figure 3. Von is used both as a temperature sensor and a damage sensor to perform diagnostics and prognostics with damage model based and condition based methods.

\section{VON SENSOR}

\subsection{Literature review}

The most critical and original part of the Von sensor is the high-voltage protection. It disconnects the low-voltage sensor from the power switch when high voltage is across it. Four main types of clamp circuits can be found in the literature (Ghimire, 2015), (Asimakopoulos, 2018), as classified and illustrated in Table 1 and Fig. 4.

Table 1. Classification of protection circuits for Von sensors

\begin{tabular}{|l|l|l|l|}
\hline Nb & Clamp method & Pros & Cons \\
\hline a) & $\begin{array}{l}\text { De-sat style with 2 } \\
\text { thermally-coupled } \\
\text { HV diodes in series }\end{array}$ & Fast & $\begin{array}{l}\text { - Fundamental issue with } \\
\text { dispersion in diode thermal } \\
\text { sensitivity }\end{array}$ \\
\hline b) & $\begin{array}{l}\text { Active MOSFET } \\
\text { clamp }\end{array}$ & Fast & $\begin{array}{l}\text { - Requirement of (SiC) HV } \\
\text { switches which are } \\
\text { necessarily high-cost } \\
\text { - Complex control }\end{array}$ \\
\hline c) & $\begin{array}{l}\text { Depletion mode } \\
\text { MOSFET }\end{array}$ & Fast & $\begin{array}{l}\text { - Requirement of HV } \\
\text { depletion mode MOSFET } \\
\text { which is not common }\end{array}$ \\
\hline d) & R-D clamp & Simple & $\begin{array}{l}\text { - Trade-off rapidity/ power } \\
\text { consumption }\end{array}$ \\
\hline
\end{tabular}

a)

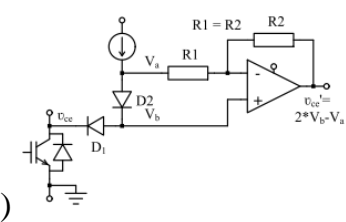

c)

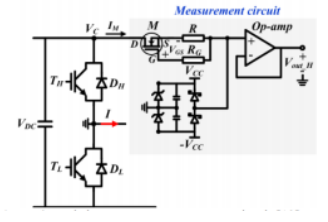

b)

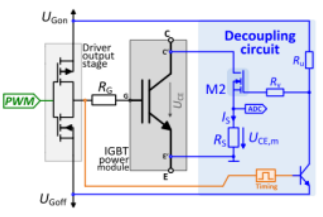

d)

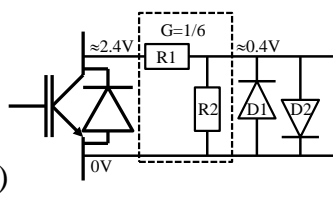

Figure 4. Examples of clamp circuits compared in Table 1.

The most important criteria for comparing Von sensors are low temperature drift, low-cost and component availability. The circuit d) with R-D clamp is performing better in this regards. Its main drawback is its relatively long time response caused by the RC time constant and the reverse-recovery charges in the clamping diodes. Decreasing the resistor value increases the power losses of the sensor when subject to highvoltage.

\subsection{Proposed Von sensor}

A Von sensor using a diode clamp was presented in (Degrenne \& Mollov, 2018a), that is capable of monitoring devices operating at high switching frequency (i.e. above $20 \mathrm{kHz}$ under typical extreme modulation depth). In this paper, the cost is mitigated through low/top-side multiplexing (Fig. 5). This circuit is demonstrated in Fig. 6 on the high and low-side pairs of a full-bridge. Its evaluation shows a precision of $\pm 3.5 \mathrm{mV}$ and a time-response of $11 \mu \mathrm{s}$. Such a prototype can be built with a MOQ (multiple Order Quantity) BOM (Bill of Material) of less $8 €$ per monitored switch. 


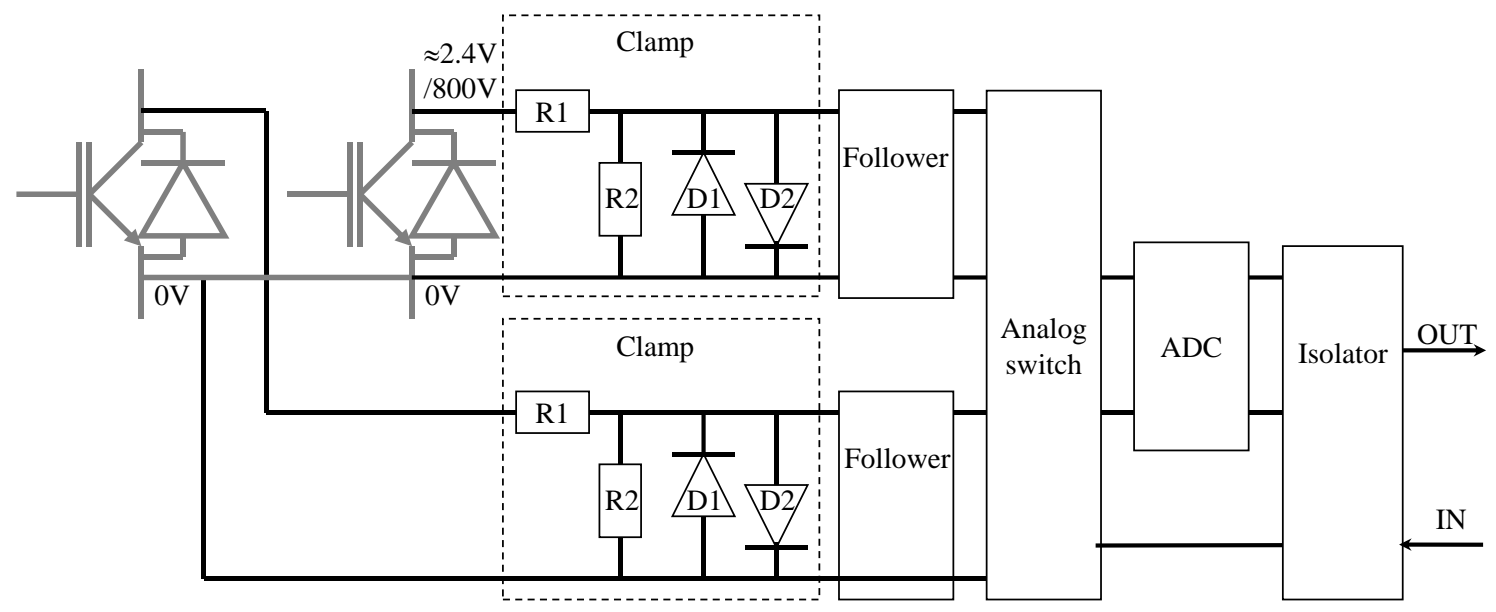

Figure 5. Multiplexed R-D clamp circuit

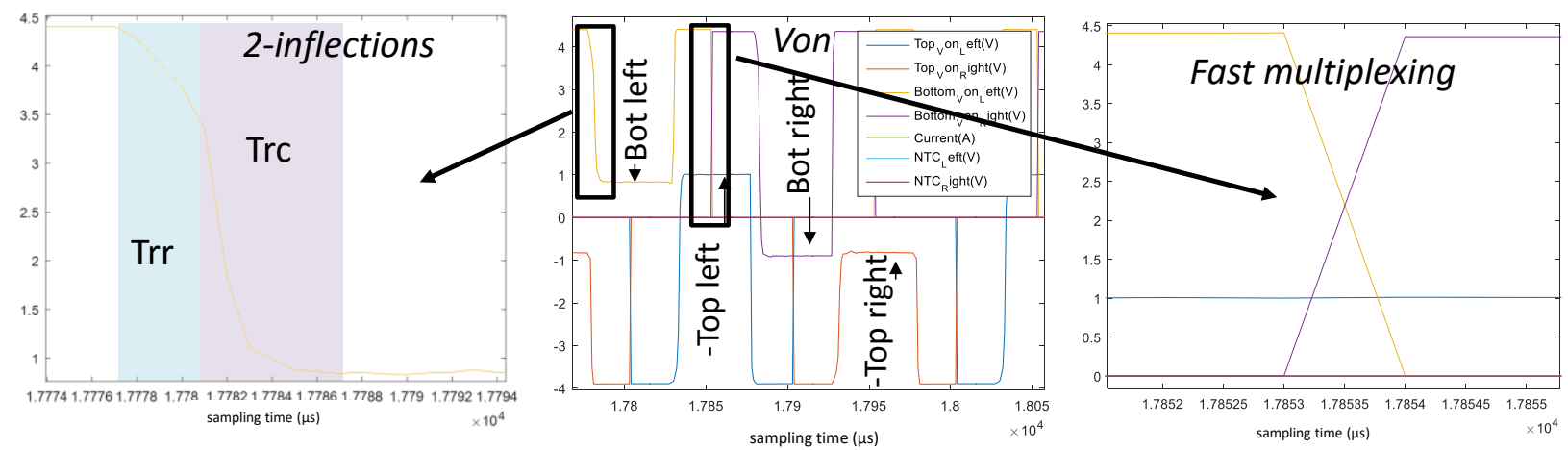

Figure 6. Von sensor output voltage waveforms monitoring a full bridge.

\section{ESTIMATION OF ELECTRICAL RESISTANCE INCREASE}

\subsection{Method}

The typical method for estimating the electrical resistance increase due to the degradation of wire-bonds is by performing Von measurement at high current and constant temperature. In (Degrenne \& Mollov, 2018a), the electrical resistance increase is assessed by performing Von measurements at ZTC (Zero Temperature Coefficient) current at any temperature, thus eliminating the effort to remove the influence of temperature variations due to variable field operating conditions. ZTC point is typically present in most IGBTs as illustrated by the static characteristic in Fig. 7.

\subsection{Results}

As compared with estimation at high load current, the sensitivity at ZTC current is proportionally decreased with the current value. For example, in Fig. 8, the static characteristics of an IGBT were acquired on-line with the previously described Von sensor for different scenario of degradation. In order to emulate degradations, wire-bonds were sectioned one by one (out of a total of 15 wire-bonds).

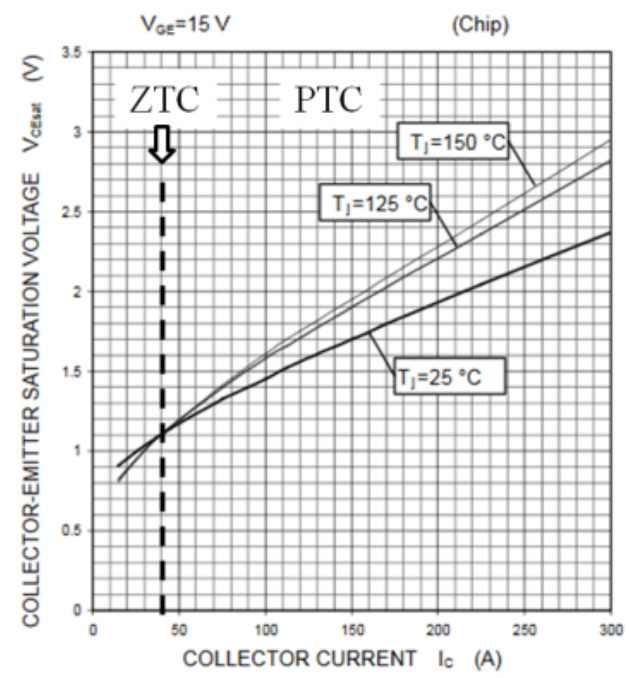

Figure 7. Typical static characteristic of an IGBT (CM150TX-24S)

The sensitivity is thus reduced by a ratio of 2.6 between measurements at 90A and at ZTC current of 35A. However, 
the sensitivity at ZTC current is sufficient to detect the liftoff of $1 / 5^{\text {th }}$ of the wire-bonds of a $1.2 \mathrm{KV} / 150 \mathrm{~A}$ IGBT module (Fig. 8). As shown in Table 2, the detection of a $5 \%$ Von increase at high current, that is typically used as a failure criteria in power cycling tests, corresponds to $35 \mathrm{mV}$ increase at ZTC current, is an order of magnitude higher than the experimentally observed precision of the Von sensor, and can thus be easily detected. The detection of finer and earlier increases such as evolution prior to the first lift-off, as used in (Degrenne \& Mollov, 2018b) and first Von jump is still a challenge at ZTC current.

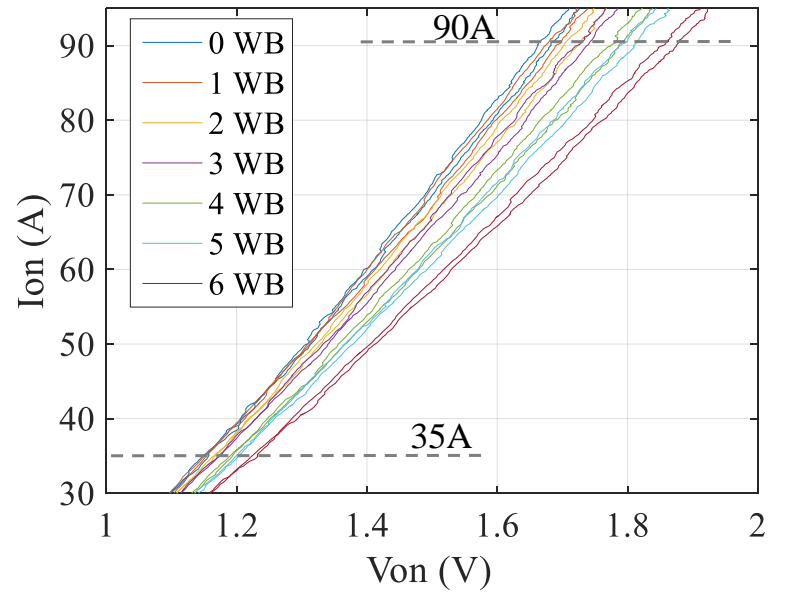

Figure 8. On-line Ion(Von) at with sectioned wire-bonds

Table 2. Typical requirements on Von sensitivity

\begin{tabular}{|l|l|l|l|}
\hline & $\begin{array}{l}\text { 1\% Von } \\
\text { increase (at } \\
\text { high } \\
\text { current) }\end{array}$ & $\begin{array}{l}\text { Average } \\
\text { Von jump }\end{array}$ & $\begin{array}{l}\text { 5\% voltage } \\
\text { increase (at } \\
\text { high } \\
\text { current) }\end{array}$ \\
\hline $\begin{array}{l}\text { @ High } \\
\text { current of } \\
90 \mathrm{~A}\end{array}$ & $18 \mathrm{mV}$ & $33.2 \mathrm{mV}$ & $90 \mathrm{mV}$ \\
\hline $\begin{array}{l}\text { @ ZTC of } \\
35 \mathrm{~A}\end{array}$ & $7 \mathrm{mV}$ & $12.8 \mathrm{mV}$ & $35 \mathrm{mV}$ \\
\hline
\end{tabular}

\subsubsection{Calibration of ZTC current}

ZTC can generally be approximated using the datasheet of the power IGBT module (Fig. 7). However, dispersions of more than $5 \mathrm{~A}$ were observed between two $1.2 \mathrm{kV} / 150 \mathrm{~A}$ switches of the same reference. On-line calibration may thus be necessary in order to increase the accuracy. Two calibration methods based on the on-line acquisition of the static curves were demonstrated in (Degrenne \& Mollov., 2018a). The first method is performing 2 static curves at different heat-sink temperatures (Fig. 9). The second method is applied in an inverter by performing one bi-directional curve at low modulating frequency (Fig. 10). In this last case, the accuracy is reduced and filtering of the local static characteristics is necessary.

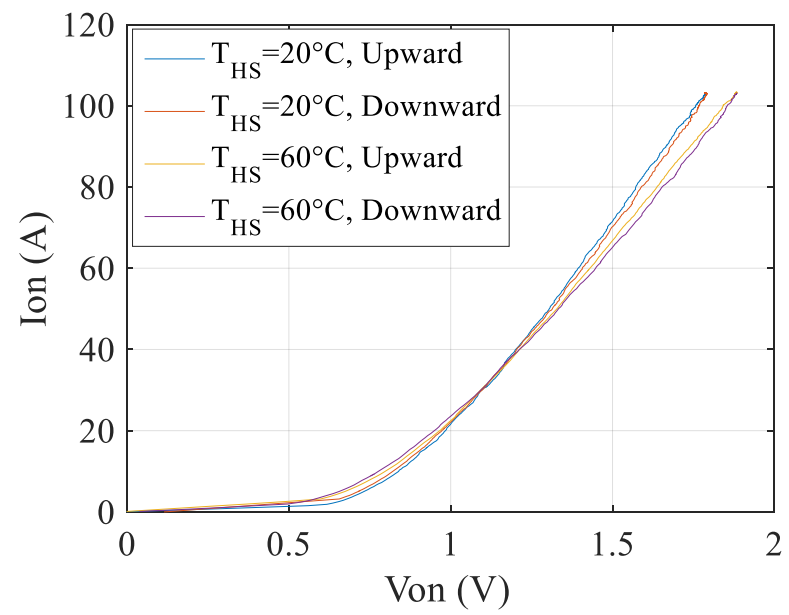

Figure 9. On-line Ion(Von) at 2 heatsink temperatures of $20^{\circ} \mathrm{C}$ and $60^{\circ} \mathrm{C}$

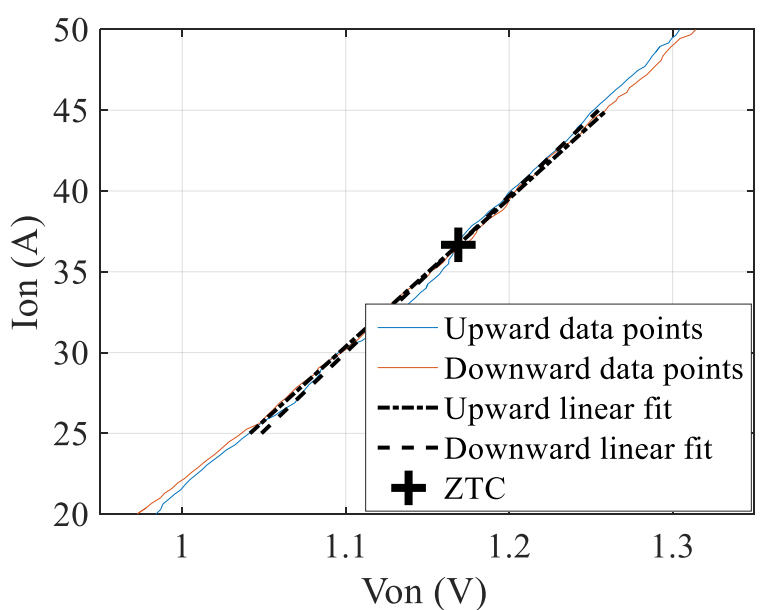

Figure 10. On-line Ion(Von) at a same heatsink temperature and during increasing and decreasing current with linear fit

\section{ESTIMATION OF JUNCTION TEMPERATURE}

\subsection{Literature review}

Von is a TSEP that can be exploited in different manners in order to estimate the junction temperature. As opposed to other TSEPs, the advantage of Von are:

- Applies to both IGBTs and Diodes

- $\quad$ Provides condition monitoring as well 
Table 3. Methods for Tj estimation with Von as a TSEP (method 4 is developed in the present paper)

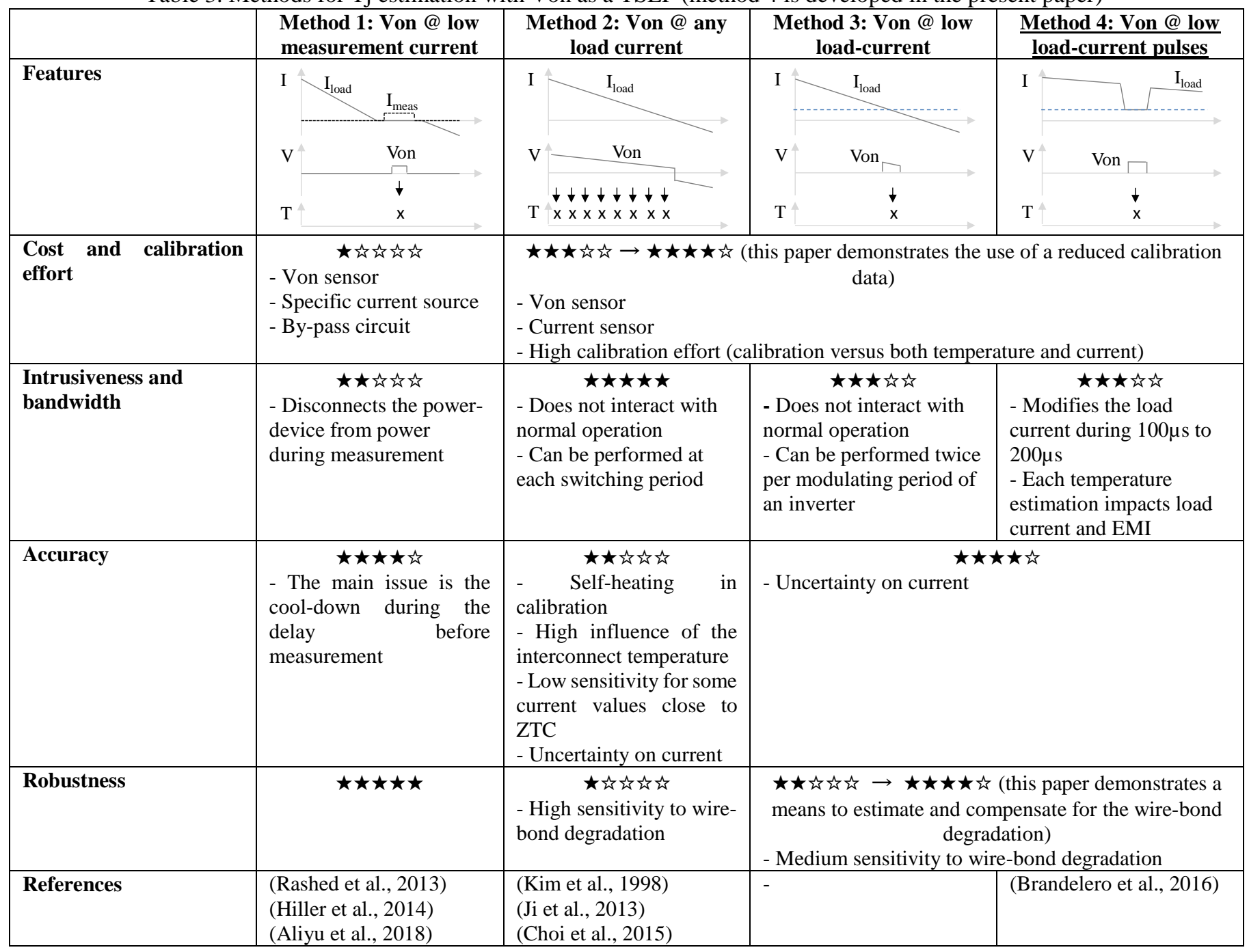

The Table 3, originally presented and discussed in (Degrenne \& Mollov, 2019) provides a literature review for implementing $\mathrm{Tj}$ estimation with Von. The selection criteria for choosing a most suitable method are the cost, the calibration effort, the intrusiveness (i.e. the on-line and insitu capability), the bandwidth, the accuracy and the robustness. In this paper, results obtained with the method 4 are presented with a way to increase the robustness to wirebond degradation.

\subsection{Proposed Method 4 and results}

The methodology for on-line temperature estimation as detailed in (Degrenne \& Mollov, 2019) includes the phases of calibration, modeling, degradation assessment, and temperature estimation as illustrated in Fig. 11.

The calibration phase is performed under low load current pulses (Fig. 12).

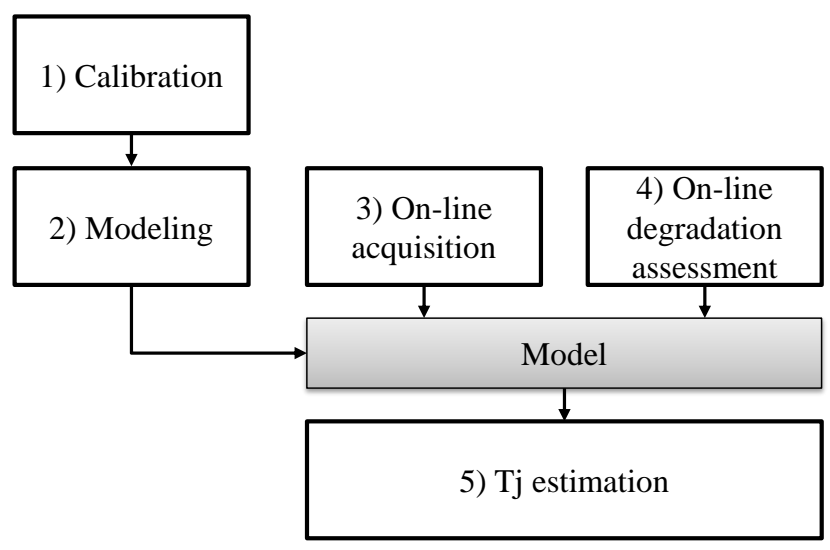

Figure 11. Proposed methodology for $\mathrm{Tj}$ estimation based on Von measurement at low load current pulses. 


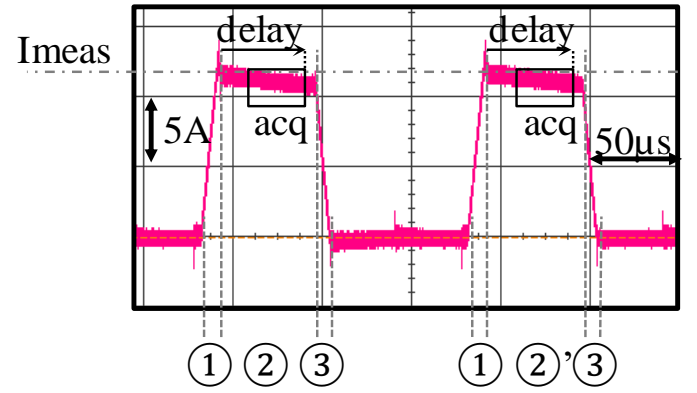

Figure 12. Example of couple of current pulses for estimation of the $\mathrm{Tj}$ of two IGBTs and two diodes of a Hbridge. ILinit $=0$ and Imeas $>0$.

Von values are monitored at various low load current levels and various heat-sink temperatures. The 3-column array of acquired data (Ths / Iload / Von) is used to fit the model of Eq. (1):

$$
\text { Von }=(a \cdot T j+b) \cdot I o n+\left(c \cdot T j+d+e \cdot T j^{2}\right)
$$

During the on-line acquisition, low-load current pulses are generated. In Fig. 13, heating and cooling of the die is performed by alternating $4 \mathrm{~s}$ sinusoidal current and $8 \mathrm{~s}$ zero current. Low-load current pulses are generated at the end of the heating and cooling phases.

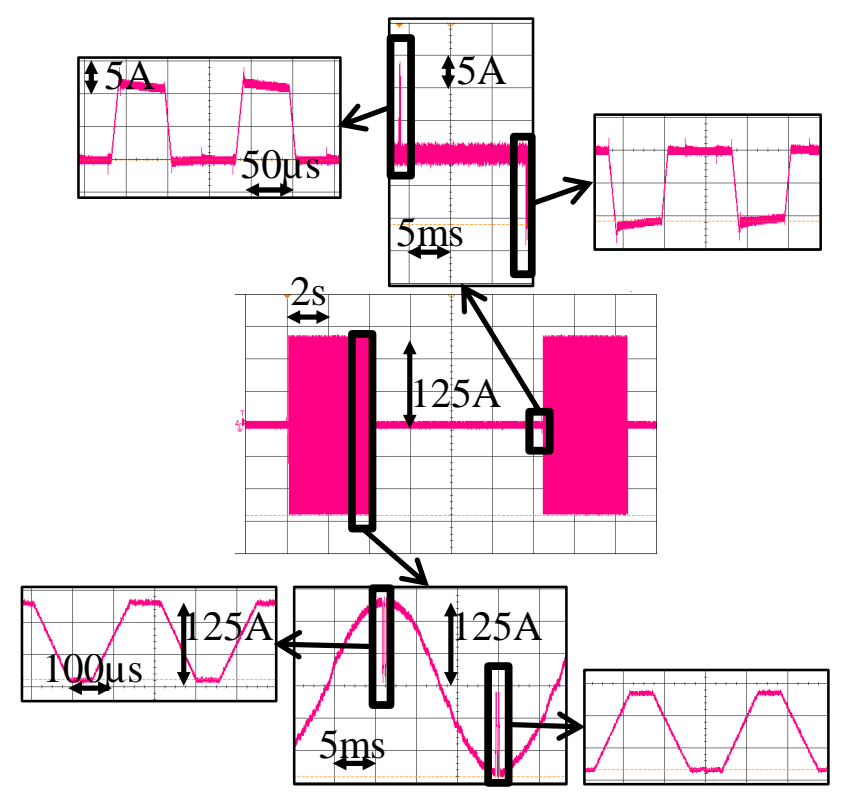

Figure 13. Low load current pulse on-line generation for $\mathrm{Tj}$ estimation at the end of the cooling phase (top) and heating phase (bottom).

The monitored Von and load current values are used together with the inverted equation for Eq. (1) and $\mathrm{Tj}$ is estimated. Experimental results demonstrate an accuracy within $\pm 3^{\circ} \mathrm{C}$ (Fig. 14).

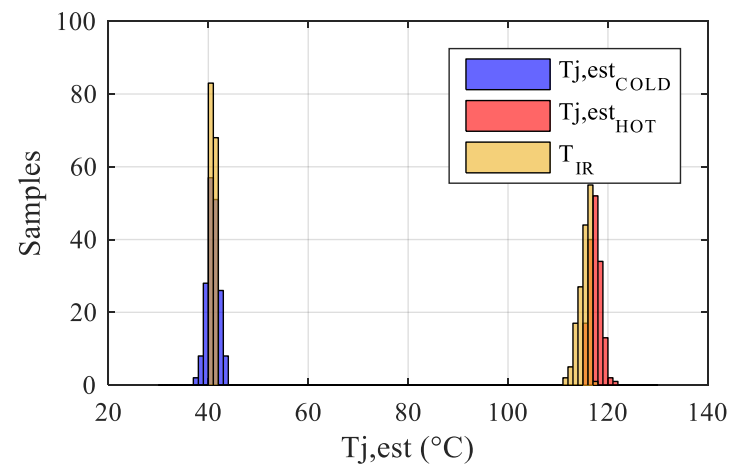

Figure 14. Cold and hot temperature estimates and IR camera values during PWM temperature cycles under $110 \mathrm{Apk}$ at $50 \mathrm{~Hz}$.

When wire-bonds lift-off, the monitored Von is slightly increase for a same effective temperature, which relates into the under-estimation of the temperature (Fig. 15)
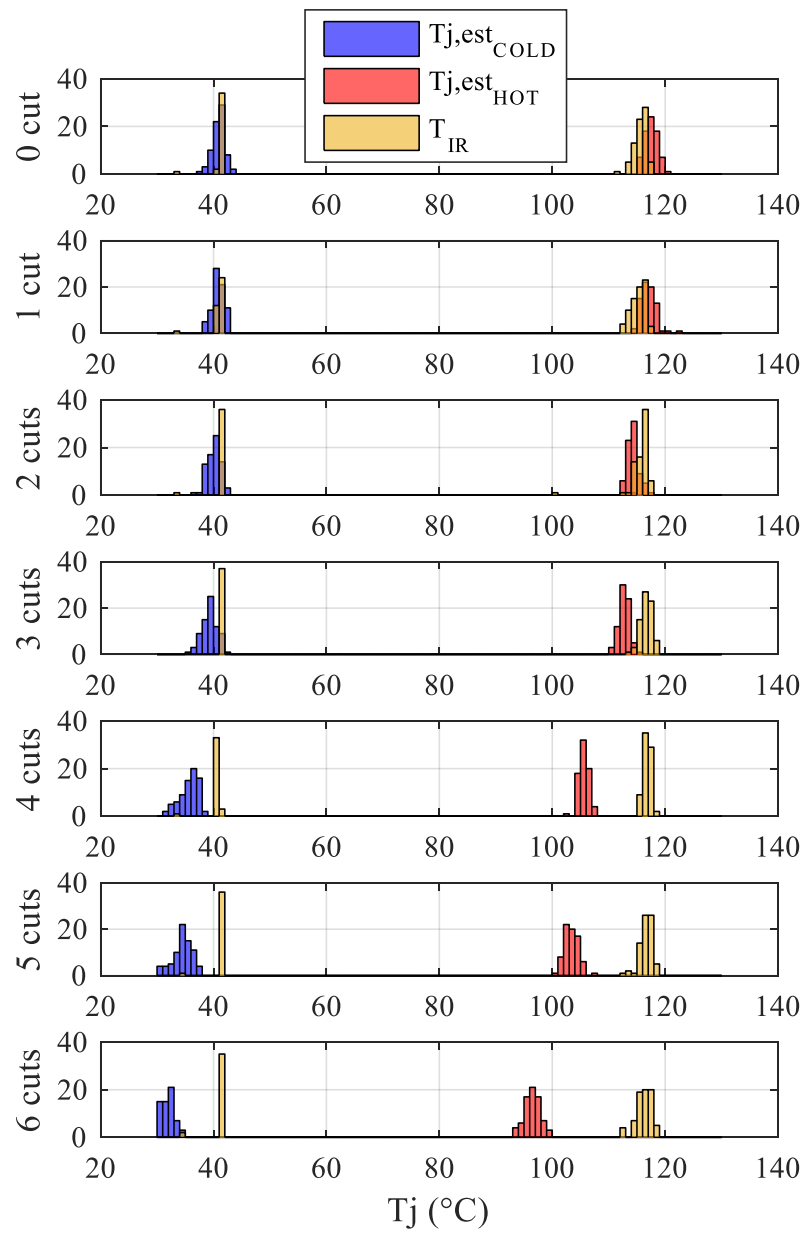

Figure 15. Cold and hot, estimated and measured temperatures with different number of sectioned wirebonds for an IGBT.

The estimation of the electrical resistance increase at ZTC can be used to correct the model (1) and the robustness of the 
temperature estimations is increased (Fig. 16). The demonstrated Kelvin-range accuracy and precision make it suitable for both protection and remaining useful lifetime estimation.
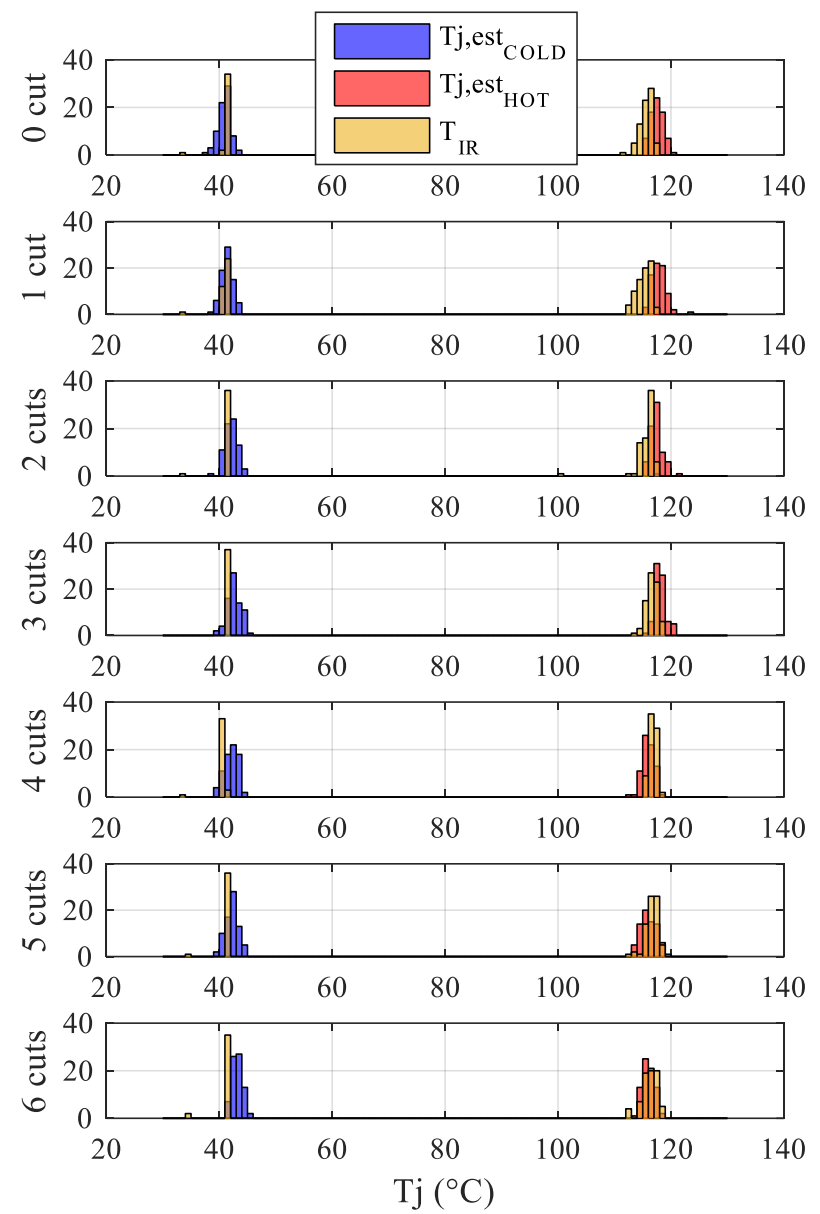

Figure 16. Cold and hot corrected temperature estimated and measured temperatures with different number of sectioned wire-bonds for an IGBT.

\section{Prediction of damage, EoL and RUL}

Now that the methods for estimating the electrical resistance increase (failure precursor) and the junction temperature (stressor) were developed, this section provides an example on how to process the information in order to generate a diagnostic and prognostic of the IGBT module.

\subsection{Literature review}

The data processing step requires a multi-disciplinary approach to combine expert knowledge in the fields of power electronics, mechanical failure propagation, and signal processing. Almost all methods in the literature require models that can either be pre-defined or auto-learned (e.g. machine learning). Physics-based models are generally preferred because they offer a logical understanding of the results and can be modified to adapt to different power modules (Yang et al., 2013), though the literature is dominated by examples of (exponential) empirical models (Celaya et al., 2011) (Dusmez et al., 2015) (Biglarbegian et al., 2018) such as Eq. (2):

$$
\Delta R=\alpha\left(e^{\beta t}-1\right)
$$

\subsection{Proposed Diagnostics and Prognostics algorithm}

The algorithm presented in Fig. 17 is detailed extensively in (Degrenne \& Mollov, 2018c). The inputs of the algorithm are Von,meas which is independent of temperature (i.e. such as electrical resistance increase) and $\mathrm{Tj}$,meas, the junction temperature measured and estimated from Von. The algorithm counts the temperature cycles with a rainflow algorithm, and uses a degradation model (or damage model) to estimate the damage (in \%) and two corresponding physical parameters which are the crack length in the wirebonds and the metallization resistivity increase. The relation between damage and physical parameters was established with FMEA (Failure Mode and Effect Analysis) and is detailed in (Degrenne et al., 2018b). An electrical model translates these parameters and the current value into an estimate of Von. This estimate is compared and combined with the measured Von in the re-sampling block. In the forecasting phase (i.e. RUL estimation phase), similar models are used but the temperature cycles are forecasted based on past observations, and no comparison and combination is performed since no measurement of Von is available.

\subsection{Results}

The algorithm is tested using power cycling data. An example of RUL estimate is shown in Fig. 18. The algorithm shows ability to estimate RUL with a reasonable error at $75 \%$ of lifetime, e.g. 5 years before End of Life (EoL) if the lifetime is 20 years (Fig. 19). At the moment of writing this paper, the different blocks of the algorithm are only roughly tuned, and the objective is mostly to show a proof of concept, rather than to evaluate its performances quantitatively.

\section{Conclusion}

This paper presents a framework that combines sensors, feature extraction methods, models, estimators and forecasting for remaining useful life estimation of power modules. Each part of this framework is important and challenging for obtaining an accurate estimation on an online system. An often overlooked problem is the calibration of the Von sensor as a temperature sensitive electrical parameter. In this paper, a method is presented where the heat-sink temperature is controlled and short current pulses are generated. This is usually not possible to perform such a calibration in the field.

The further steps of this study will be to adapt it to a fully online converter environment, and to quantify its performances experimentally. 


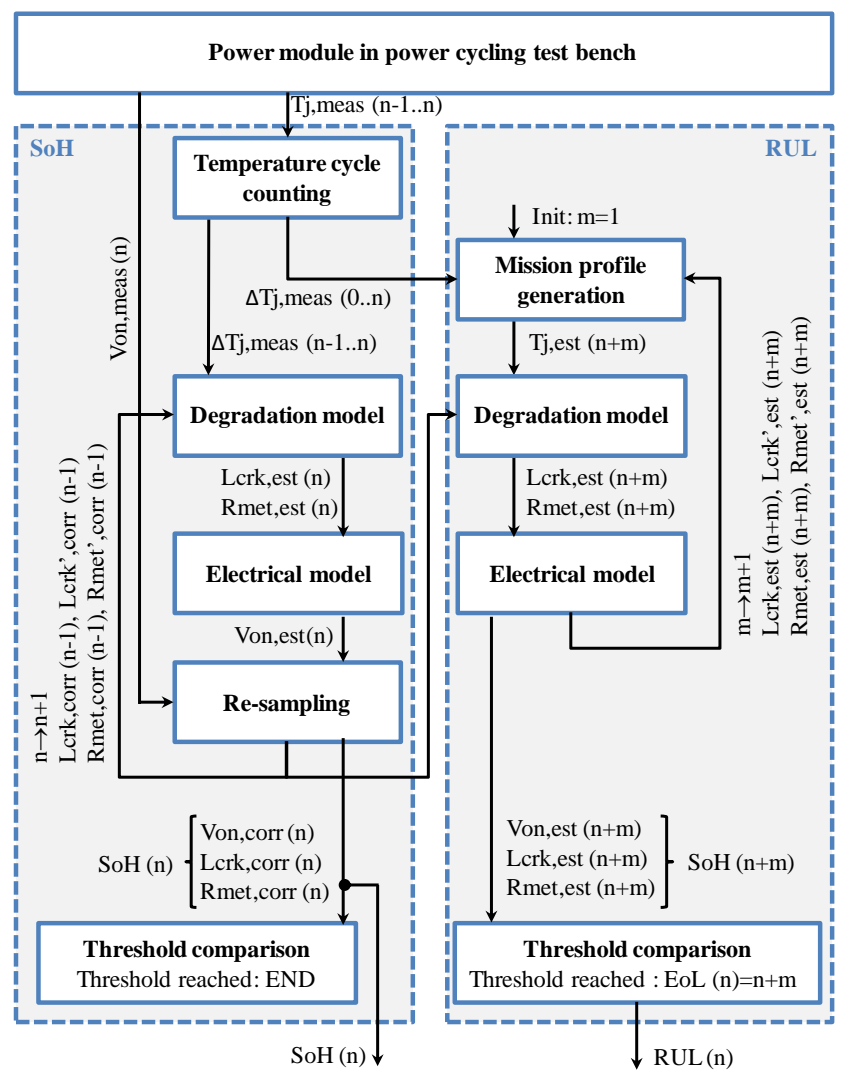

Figure 17. General view of the algorithm for SoH and RUL estimation

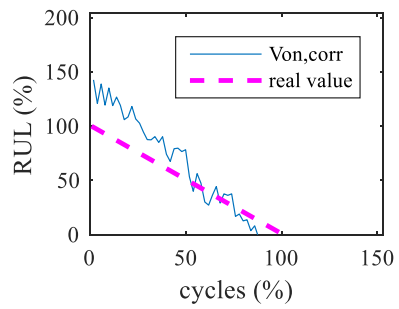

Figure 18. Mean estimation of the RUL as a function of number of cycle for a DUT.
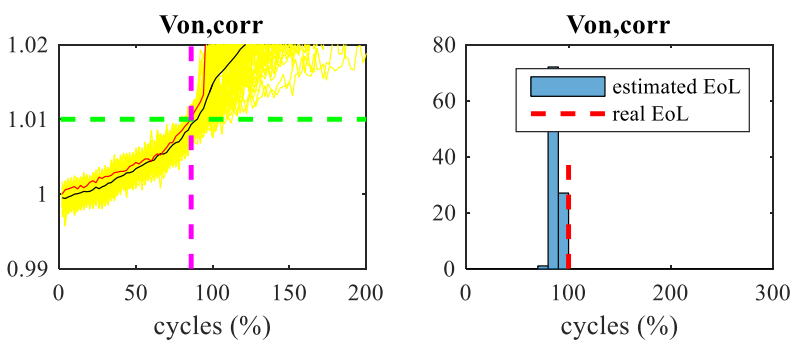

Figure 19. Details of the algorithm activated after $75 \%$ cycles. Identification and extrapolation of the $\mathrm{SoH}$ states (left) and corresponding EoL estimates (right). On the left, the particles and their mean are yellow and black, the real value is red, dashed curves show the activation time (magenta) and the threshold (green).

\section{REFERENCES}

Aliyu, A. M. \& Castellazzi, A. (2018). Prognostic System for Power Modules in Converter Systems Using Structure Function. IEEE Trans. Power Electron., vol. 33, no. 1, pp. 595-605, 2018.

Asimakopoulos, P. (2018). On integrity assessment of IGBTbased power stacks used in magnet power supplies for particle accelerators. PH. D. Thesis, U. of Chalmers.

Biglarbegian, M., Mostafavi, S., Hauer, S., Nibir, S. J., Kim, N., Cox, R., \& Parkhideh, B. (2018). On Condition Monitoring of High Frequency Power GaN Converters with Adaptive Prognostics. In APEC 2018.

Brandelero, J., Ewanchuk, J., \& Mollov, S. (2016). Online Junction Temperature Measurements for Power Cycling Power Modules with High Switching Frequencies. ISPSD 2016. https://doi.org/10.1109/ISPSD.2016.7520810

Celaya, J., Saxena, A., Saha, S., \& Goebel, kai F. (2011). Prognostics of Power MOSFETs under Thermal Stress Accelerated Aging using Data-Driven and Model-Based Methodologies. In PHMC 2011.

Choi, U. M., Blaabjerg, F., Iannuzzo, F., \& Jørgensen, S. (2015). Junction temperature estimation method for a $600 \mathrm{~V}, 30 \mathrm{~A}$ IGBT module during converter operation. Microelectronics Reliability, 55, 2022-2026. https://doi.org/10.1016/j.microrel.2015.06.146

Degrenne, N., Ewanchuk, J., David, E., Boldyrjew, R., Mollov. (2015). A Review of Prognostics and Health Management for Power Semiconductor Modules. In PHM society 2015.

Degrenne, N., \& Mollov, S. (2018a). On-line Health Monitoring of Wire-Bonded IGBT Power Modules using On-State Voltage at Zero-TemperatureCoefficient. In PCIM 2018.

Degrenne, N., \& Mollov, S. (2018b). ExperimentallyValidated Models of On-State Voltage for Remaining Useful Life Estimation and Design for Reliability of Power Modules. In CIPS 2018.

Degrenne, N., \& Mollov, S. (2018c). Diagnostics and Prognostics of Wire-Bonded Power Semi-Conductor Modules subject to DC Power Cycling with Physically-Inspired Models and Particle Filter. In PHME 2018 (pp. 1-10).

Degrenne, N., \& Mollov, S. (2019). Robust On-line Junction Temperature Estimation of IGBT Power Modules based on Von during PWM Power Cycling. In IWIPP 2019.

Dusmez, S., \& Akin, B. (2015). Remaining Useful Lifetime Estimation For Degraded Power MOSFETs Under Cyclic Thermal Stress. In ECCE 2015.

Ghimire, P. (2015). Real Time Monitoring and Wear Out of Power Modules. Ph.D. Thesis, U. of Aalborg.

Goebel, K., Daigle, M., Saxena, A.,Sankararaman, S., Roychoudhury, I. \& Celaya, J.R. (2017). Prognostics: the Science of Predictions. 
Hiller, S., Herold, C. \& Lutz, J. (2014). Measurement of Tvj in a B6 IGBT inverter for electric vehicles using the Vce(T)-method. ISPS'2014.

Ji, B., Pickert, V., Cao, W., and Zahawi, B.. (2013). In situ diagnostics and prognostics of wire bonding faults in IGBT modules for electric vehicle drives. IEEE Trans. Power Electron., vol. 28, no. 12, pp. 5568-5577, 2013.

Kim, Y.-S. K. Y.-S., \& Sul, S.-K. S. S.-K. (1998). On-line estimation of IGBT junction temperature using onstate voltage drop. IAS 1998.

Lutz, J., Schlangenotto, H., Scheuermann, U., \& De Doncker, R. (2011). Semiconductor power devices: Physics, characteristics, reliability. Berlin, Heidelberg: Springer Berlin Heidelberg.

Rashed, A., Forest, F., Huselstein, J. J., Martire, T., \& Enrici, P. (2013). On-line [TJ, Vce] monitoring of IGBTs stressed by fast power cycling tests. EPE 2013.

Yang, L., Agyakwa, P. A., \& Johnson, C. M. (2013). Physicsof-failure lifetime prediction models for wire bond interconnects in power electronic modules. IEEE Transactions on Device and Materials Reliability, 13(1), 9-17. 